\title{
Aridity trend in the Middle East and the adjacent areas
}

\author{
Hossein Sahour $^{1 *}$, Mehdi Vazifehdan ${ }^{2}$, Fahad Alshehri ${ }^{1 \text { and } 3}$ \\ ${ }^{1}$ Department of Geological and Environmental Sciences, Western Michigan University, MI 49008, USA \\ ${ }^{2}$ Department of Statistics, Western Michigan University, MI 49008, USA \\ ${ }^{3}$ Geology and Geophysics Department, King Saud University, Riyadh 11451, Saudi Arabia \\ *Corresponding author Hossein.sahour@wmich.edu
}

\begin{abstract}
Available water resources in the Middle East, as one of the most water-scarce regions of the world, have undergone extra pressure due to climatic change, population growth, and economic development during the past decades. The objective of this study is to detect the trends and quantify the changes in aridity with respect to precipitation and potential evapotranspiration in 20 countries of the Middle East and the adjacent area. A Pixel-wised trend analysis was conducted on precipitation, potential evapotranspiration, and aridity index for 71 years from 1948 to 2018. A nonparametric Mann-Kendall test was used over 14106 points in the study area to detect the trends at monthly and annual time scales. Results showed statistically significant $(|Z|>1.96)$ upward trends in aridity (a downward trend in aridity index) up to 96 percent from December through September in most parts of the region. Aridity in October and November had a downward tendency in most parts of the study area. At the annual time scale, 62.5 percent of the statistically significant trends in aridity were found to be upward (up to 96 percent increase in aridity) due to the combined effects of the decrease in precipitation and the increase in potential evapotranspiration and 37.5 percent of the detected trends were downward (up to 61 percent decrease in aridity). The highest and the lowest trends in aridity were found in the north of Sudan (96 percent increase in aridity) and Eastern Arabia (61 percent decrease in aridity), respectively.
\end{abstract}

Keywords: Climate Change, Aridity, Precipitation, Mann-Kendall, Middle East 


\section{Introduction:}

The global rise in greenhouse gases is one of the major causes of the change in climate variables (e.g., temperature, evapotranspiration, and precipitation) (Bryan, 1996; Wang et al., 2014; Chen et al., 2019; Mudelsee, 2019; Douville et al., 2020). In recent years, several studies have reported compelling evidence on the impact of climate change on water resources across the globe (Bouraoui et al., 1999; Kamga, 2001; Risbey, 2011; Ziervogel et al. 2019; Said et al., 2019; Schilling et al., 2020; Soto-Navarro el al.,2020 ). Significant shifts have occurred in the water cycle due to the combined effects of climate change and human activities in many parts of the world. Such changes eventually alter water resource distribution (Oki and Kanae, 2006; Pradhan et al., 2019; Llopart et al., 2020).

Aridity is defined as the degree to which a climate lacks adequate, life-promoting moisture (Glickman, 2000). Aridity is the outcome of dry and descending air. Therefore, aridity is often found in areas where anticyclonic conditions are persistent, as is the case in the regions lying under the anticyclones of the subtropics (Some'e et al., 2012). An aridity index can measure the intensity of aridity. Aridity indices help to identify, locate, or delimit regions that undergo water deficiency, a condition that can severely affect the efficient utilization of lands for life-promoting activities (e.g., agriculture and stock farming).

The impact of climate change on water resources is even more pronounced in dry climates with low precipitation and high evaporation rate. Arid regions are usually characterized by frequent and severe droughts (Grove, 1985). The Middle East is one of the hottest and driest regions of the world in which available water is less than 20 percent of the global average. In the past decades, the water resources in the region have been depleting faster than before due to the combined impacts of climate change, rapid population growth, economic development, and frequent drought. (Falkenmark and Lannerstad, 2005).

Precipitation, temperature, and evaporation are important hydro-climate variables that determine the balance in the hydrologic cycle and availability of water resources (Mohmmadian et al., 2017; Gholami et al., 2017 and 2019). Most Middle Eastern countries are characterized by severe water deficiency and high evaporation rates. Therefore, monitoring changes in aridity is crucial for any long-term water resource utilization and management plans. Long term monitoring of climate variables helps to build resilience to 
mitigate the harmful impacts of climatic changes through adapting appropriate strategies for new climatic scenarios. Trend analysis of climate variables is a useful tool to investigate the behavior and changes associated with climate variables. Numerous studies have been conducted to study the trend analysis of precipitation and evaporation all over the globe (Partal and Kahua, 2006; Dinpashoh et al., 2011; Irmak et al., 2012; Jhajharia et al., 2012 and 2014; Fathian et al., 2015; D'Oria et al., 2017; Xing et al., 2018; Tehrani et al., 2019; Güçlü 2020).

Time series analysis of precipitation, evaporation, temperature, and aridity index have been conducted in numerous case studies in the Middle East. Tabari et al., 2012, investigated the temporal pattern of monthly and annual aridity index in the north and northwest of Iran for a period of 40 years (1966 - 2005) and concluded that the aridity in the region increased and the trends were more pronounced in the semi-arid sections of the study area. Some'e, et al., 2012 conducted a spatiotemporal trend analysis in arid and semiarid regions of Iran for 40 years (1966 - 2005). They found statistically significant negative trends in aridity index (more dryness) in 55 percent of the stations and a significant positive trend in two stations. Patal and Kahya, 2005 used a non-parametric method to detect the trends in mean annual and monthly precipitation in Turkey for a 65-year study period (1929 to 1993). They found a noticeable decrease in the mean annual precipitation in western and southern parts of Turkey as well as along the coast of the Black sea. In Saudi Arabia, trend analysis was conducted on extreme temperature indices for 30 years (1981-2010), and results showed a significant increase in the annual occurrence of warm days/nights and a decrease in the annual occurrence of cold days/nights (Almazroui et al., 2013). Trend analysis of average annual temperature, annual precipitation, and annual aridity index in Israel showed positive trends in temperature and aridity among the 12 investigated stations for the period 1970-2002 (Kafle and Bruins, 2007). In Egypt, the trend analysis of rainfall in 31 stations showed that 77 percent of the detected trends were negative, concluding a decrease in precipitation in Egypt (Gado et al., 2019).

In all the research mentioned above, trend analyses were applied to local field-based data, which reflect the values for those specific points and not for the area between the stations. The issue of spatial gaps between the stations was addressed in previous studies (e.g., Some'e, et al., 2012; Tehrani et al., 2019) using Inverse 
distance weighting (IDW) method to transfer data from multiple locations. However, the assigned values to unknown points in the IDW method are only estimated with a weighted average of the values, and it does not consider the other crucial factors such as heterogeneity of landscapes and the elevation change between stations (Livneh et al., 2014). To better understand the patterns and effects of climate change on water resources, spatially, and temporally continuous data at a fine resolution grid are needed (Hasan et al., 2019; Sahour et al., 2020). In this research, we conducted a pixel-wise trend analysis of aridity index over the entire Middle East and adjacent regions for 71 years (1948 to 2018), based on a detailed review of monthly precipitation and annual potential evapotranspiration. The trend analysis in this study was performed at the pixel level in the gridded data. The time series for individual pixel (data point) were extracted, and trend analysis was conducted for each pixel independently. Our climatic trend analysis evaluates spatiotemporal trend analysis of the following variables: monthly and annual precipitation (P), monthly and annual potential evapotranspiration (PET), and monthly and annual aridity index (P/PET).

\section{Study area}

The study area (Figure 1) is the Middle East (hereafter referred to as ME) including 20 countries (Armenia, Azerbaijan, Bahrain, Cyprus, Egypt, Eritrea, Iran, Iraq, Israel, Jordan, Kuwait, Lebanon, Oman, Qatar, Saudi Arabia, Sudan, Syria, Turkey, United Arab Emirates, and Yemen) with a population of 432 million (Roudi-Fahimi and Kent, 2007). The region is diverse in its climate and landscape, from the snowy summits of the Eastern Anatolia down to the empty quarter of the Arabian Peninsula (AP). Considering the aridity index, which is the ratio of precipitation to potential evapotranspiration, in previous studies, the hyper-arid area was found in Egypt, Saudi Arabia, and Sudan (Terink et al., 2013). Iran, the northern coast of Egypt, southwest of Saudi Arabia, and the western coastal region of the ME were defined as arid to semi-arid. The humid area was found in some parts of Turkey, Iran, Iraq, western Syria, and Lebanon (Terink et al., 2013). The major challenge in the ME region is to manage the low annual precipitation rate and limited available water resources for the water demands in agricultural, industrial, and urban populations sectors. 
The ME has one of the fastest-growing populations in the world, with an average annual growth rate of 2.1 percent between 1990 and 2003 (The World Bank, 2005). The population was growing about 100 million

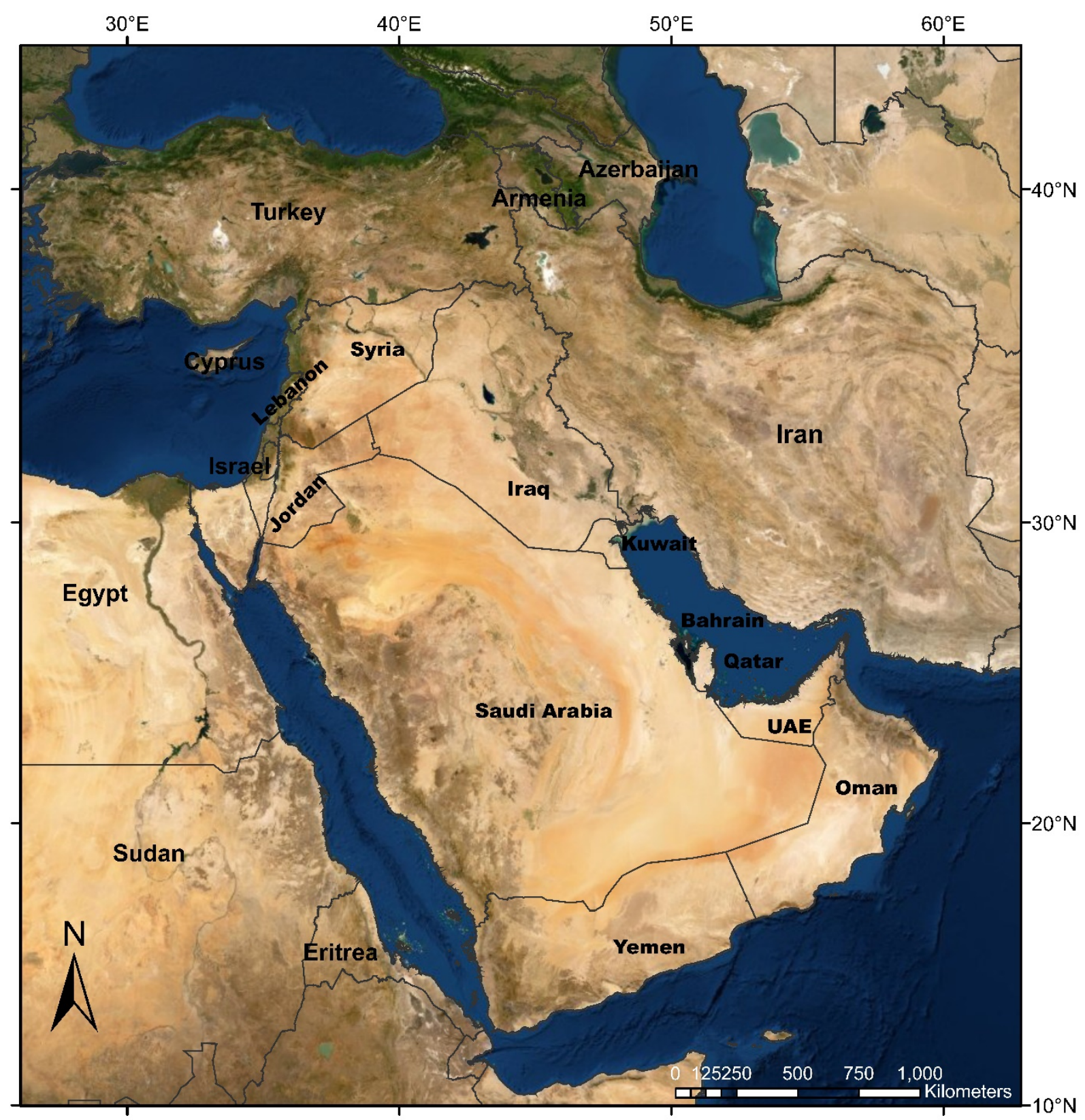

Figure1. Location of the study area.

in 1960, 311 million in 2006, and projected to be more than 430 million in 2025 (Joffe, 2005), bringing the average amount of water per capita in the region far lower the scarcity level. According to the World Bank 
(2007), most of the countries in ME cannot meet their current water demands, and the situation is getting worse due to climate change and the increase in population. The water resources in the ME are mostly used in agricultural sectors, which helps the ME regional economies. Iran, Lebanon, Turkey have a relatively better situation in terms of renewable water; however, within-country and within-year variation in precipitation are problematically significant. The majority of the ME countries with scarce renewable water resources are highly dependent on non-renewable groundwater sources and seawater desalination. These countries include Bahrain, Jordan, Kuwait, Libya, Oman, Qatar, Saudi Arabia, the United Arab Emirates, and Yemen. Some others, including Syria, Iraq, and Egypt, are dependent on the inflow of trans-boundary rivers such as the Nile, the Tigris, and the Euphrates (World Bank, 2007).

\section{Data and Methodology}

\subsection{Data}

The NOAH output of the Global Land Data Assimilation System (GLDAS-NOAH) provides global precipitation and potential evapotranspiration data. In this research, the time series of monthly precipitation (P) and potential evapotranspiration (PET) were used to calculate the monthly aridity index (P/PET) for 71 years (1948 to 2018). The variables are available in a gridded format at a $0.25^{\circ} \times 0.25^{\circ}$ spatial resolution. GLDAS uses advanced numerical models of physical processes to integrate data from multiple groundbased and space-based observing systems to produce spatially and temporally continuous water and energy states and fluxes data. The data is available at https://disc.gsfc.nasa.gov/datasets?keywords=GLDAS. Potential evapotranspiration (PET) is described as the amount of water that could be released to the atmosphere where it available. It is a function of surface and air temperatures, insolation, and wind, all of which affect water-vapor concentrations immediately above the evaporating surface. The broad definition of dryland is a place where the annual PET exceeds annual precipitation. The potential evapotranspiration can be calculated through the following equation: 


$$
E T_{0}=\frac{0408\left(R_{n}-G\right)+\frac{900 \gamma\left(e_{s}-e_{a}\right) U_{2}}{T_{\text {mean }}+273}}{\Delta+\gamma\left(1+0.34 U_{2}\right)}
$$

Eq.1

Where $E T_{0}$ is the reference $E T\left(\frac{m m}{d}\right), R_{n}$ is the net radiation $\left(\frac{M J}{m^{2} d}\right), G$ is the soil heat flux $\left(\frac{M J}{m^{2} d}\right), \gamma$ is the psychrometric constant $\left(\frac{k P a}{{ }^{\circ} C}\right), e_{s}$ is the saturation vapor pressure $(k P a), e_{a}$ is the actual vapor pressure $(\mathrm{kPa}), \Delta$ is the slope of the saturation vapor pressure-temperature curve $\left(\frac{\mathrm{kPa}}{{ }^{\circ} \mathrm{C}}\right), T_{\text {mean }}$ is the average daily air temperature $\left({ }^{o} C\right)$, and $U_{2}$ is the mean daily wind speed at $2 \mathrm{~m}\left(\frac{\mathrm{m}}{\mathrm{s}}\right)$.

Precipitation in this research refers to the total amount of rainfall and snow water equivalent. The monthly aridity index (P/PET) was calculated for each month (UNEP, 1992). Based on the aridity index, climates can be classified into four groups (Table 1). The more precipitation, the higher the aridity index. In other words, a drier area has a lower aridity index. Regarding that, a negative trend in the aridity index means that the climate is moving toward aridity and vice versa.

Table 1. Classification of the climates in the study area based on aridity index (UNEP, 1992)

\begin{tabular}{ccc}
\hline Classification & Aridity Index & Area (percent)* \\
\hline Hyper-arid & $\mathrm{AI}<0.05$ & 49.34 \\
\hline Arid & $0.05<\mathrm{AI}<0.20$ & 28.43 \\
\hline Semi-arid & $0.20<\mathrm{AI}<0.50$ & 8.15 \\
\hline Dry sub-humid & $0.50<\mathrm{AI}<0.65$ & 10.73 \\
\hline
\end{tabular}

*Percentage relative to the study area

\subsection{Methodology}

In this section, we describe the methods we used for monthly and annual trend analysis to detect the trends in precipitation, potential evapotranspiration, and the aridity index. 


\subsubsection{Mann-Kendall (MK) test for monotonic trend}

The primary purpose of the Mann-Kendall (Mann, 1945; Kendall, 1975) test (MK) is to statistically assess if there is a monotonic upward or downward trend for the variable of interest over time. A monotonic upward (or downward) trend means that the variable consistently increases (decreases) over time, but the trend itself may or may not be linear. The MK test can be used to test if the trend is different from zero. In a regression analysis, it is required that the residuals from the fitted regression line be normally distributed, an assumption that is not required by the MK test since the MK test is non-parametric (distribution-free). We note that the Mann-Kendall test may be viewed as a non-parametric test for zero slopes of the linear regression of time-ordered data against time. The assumptions underlie the MK test is first when no trend is present, the measurements obtained over time are independent and identically distributed. The assumption of independence means that the observations are not serially correlated over time (If serially correlated, the pre-whitening procedure may be applied); Second, The observations obtained over time are representative of the actual conditions at sampling times; and third, the sample collection, handling, and measurement methods provide unbiased and representative observations of the underlying populations over time.

Let $x_{1}, x_{2}, \ldots, x_{n}$ be the time series of observations collected at times $i=1,2, \ldots, n$. Then the Mann-Kendall (Eq.2) Statistic is (Gilbert, 1987):

$$
S=\sum_{i=1}^{n-1} \sum_{j=i+1}^{n} \operatorname{sgn}\left(x_{i}-x_{j}\right)
$$

where 


$$
\operatorname{sgn}\left(x_{i}-x_{j}\right)=\left\{\begin{array}{l}
1,\left(x_{i}-x_{j}\right)>0 \\
0,\left(x_{i}-x_{j}\right)=0 \\
-1,\left(x_{i}-x_{j}\right)<0
\end{array}\right.
$$

If $\mathrm{S}$ is a large positive number, measurements taken later in time tend to be larger than those taken earlier. Similarly, if S is a large negative number, measurements taken later in time tend to be smaller. Suppose the goal is to test the null hypothesis, ${ }^{H_{0}}$ of no trend against the alternative hypothesis $H_{A}$, of either an upward or downward trend. Then $H_{0}$ is rejected in favor of $H_{A}$, if the absolute value of $S$ is a large enough positive number.

\subsubsection{Z-Statistic}

$\mathrm{Z}$ statistic was used to determine the statistical significance of the trends. The variance of $S_{\text {is given by }}$

$$
\operatorname{Var}(S)=\frac{1}{18}\left[n(n-1)(2 n+5)-\sum_{k=1}^{m} t_{k}\left(t_{k}-1\right)\left(2 t_{k}+5\right)\right]
$$

Eq. 3

Where $m$ is the number of tied groups and $t_{k}$ is the number of observations in the group. Then the MK test statistic, $Z_{M K}$, can be computed as

$$
Z_{M K}=\left\{\begin{array}{l}
\frac{S-1}{\sqrt{\operatorname{Vars}(S)}}, S>0 \\
0, S=0 \\
\frac{S+1}{\sqrt{\operatorname{Vars}(S)}}, S<0
\end{array}\right.
$$

Eq. 4 
A positive (or negative) $Z_{M K}$ value indicates that the data tends to increase (or decrease) with time. To test the null hypothesis

$H_{0}$ : There is no monotonic trend (strictly increasing or strictly decreasing, almost everywhere), versus the alternative hypothesis

$H_{A}:$ Upward or downward monotonic trend.

Then at the type I error rate $\alpha, H_{0}$ is rejected and $H_{A}$ is accepted if $\left|Z_{M K}\right| \geq Z_{1-\frac{\alpha}{2}}$.

The trends with values of $|Z|>1.96$ were considered to be statistically significant.

\subsubsection{Sen's Slope}

This section shows how to estimate the true slope (change per unit time) by using a non-parametric procedure developed by Sen (1968). The procedure in sen's slope is an extension of a test by Theil (1950), which is illustrated by Hollander and Wolfe (1973). Let $x_{1}, x_{2}, \ldots, x_{n}$ be the time series of observations collected at times $i=1,2, \ldots, n_{\text {For all }} 1 \leq i<j \leq n_{\text {let }}$

$$
\beta=\operatorname{Median}\left(\frac{x_{i}-x_{j}}{i-j}\right)
$$

Eq.5

which is the median of all combinations of the recorded pairs of data. Sen's method is not significantly affected by data errors or outliers, and it can be computed for the datasets with missing values. Sen's estimator is closely related to the Mann-Kendall test (Hollander and Wolfe 1973). 


\subsubsection{Pre-Whitening}

As noted above (Mann-Kendall test section), the Mann-Kendall test requires the time series to be serially independent (not serially correlated). Von Storch (1999) proposed a procedure called pre-whitening to eliminate this serial correlation effecting the Mann-Kendall test. The idea of the pre-whitening process is to remove the serial correlation assuming a lag-one autoregressive model, and then apply the MK test to the serially independent residuals. So that a serially correlated time series $\left(y_{i}\right)$ is pre-whitened by $x_{i}=y_{i}-r_{1} y_{i-1}$ where $r_{1}$ is the lag-one serial correlation coefficient calculated by (Eq.6)

$$
r_{1}=\frac{\left(\frac{1}{n-1}\right) \sum_{i=1}^{n-1}\left[y_{i}-E\left(y_{i}\right)\right]\left[y_{i+1}-E\left(y_{i}\right)\right]}{\left(\frac{1}{n}\right) \sum_{i=1}^{n}\left[y_{i}-E\left(y_{i}\right)\right]^{2}}
$$

Where

$$
E\left(y_{i}\right)=\frac{1}{n} \sum_{i=1}^{n} y_{i}
$$

\subsubsection{Relative change}

The relative change of the annual and monthly aridity indices were calculated using the following equation

$$
x=\frac{\mathrm{L} \times \beta}{|\bar{X}|} \times 100
$$

Where $\mathrm{L}$ is the length of trend (number of months of years), $\beta$ is the slope of the trend, and the $|\bar{X}|$ is the absolute average value of the time series. 
All methods described above for the trend analysis were conducted in a pixel level. There were 14106 pixels (locations) for each variable (P, PET and AI) covering the study. Each pixel had a unique time series representing the values for that specific variable over time. Therefore, the time series analysis for each pixel was independent from adjacent pixels.

\section{Results and discussion}

Figure 2 shows the mean annual values of precipitation, PET, and AI. The mean annual values were calculated by averaging the monthly values. According to figure 2, the mean annual precipitation within the study period (1948-2018) was lowest in the west of Egypt (2 to $10 \mathrm{~mm} /$ year) and highest in the northeast and west of turkey (750 to $1000 \mathrm{~mm} /$ year). The potential evapotranspiration (PET) in the ME varies from $800 \mathrm{~mm} /$ year in north and northeast of Turkey to $3000 \mathrm{~mm} /$ year in the southeast of Iran, the southeast part of Saudi Arabia, southeast of Sudan and northeast of Yemen. 


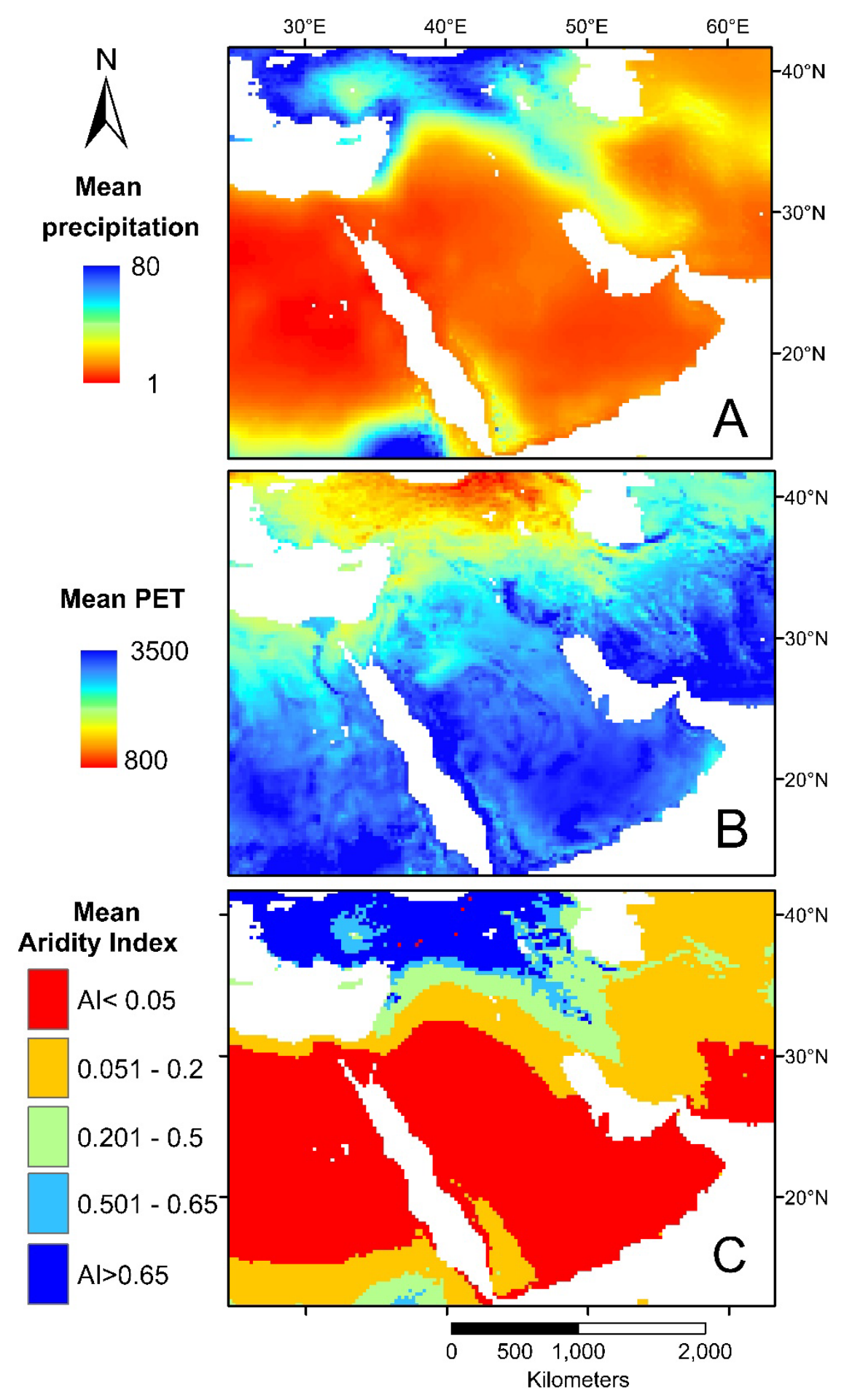

Figure 2. (A) Mean annual precipitation, (B) Mean annual potential evapotranspiration (PET), and (C) mean annual aridity index. The annual mean values for all three variables (A through $\mathrm{C}$ ) were calculated for 71 years (1948 to 2018) by averaging the monthly values. 


\subsection{Monthly trends for precipitation (P)}

Trend analysis of monthly precipitation (figure 3 and figure 4) was conducted for each month of the year for the study period (1948-2018). For the January, February, and March, statistically significant $(|Z|>1.96)$ upward trend (from 0.3 to $0.5 \mathrm{~mm} /$ month) were observed in the northwest of Turkey, and southwest of Iran (figure 3 and 4). Statistically significant (figure 3) downward trend (up to $0.8 \mathrm{~mm} / \mathrm{year}$ ) was detected on the west side of Turkey, east of Iran, the north of Iraq, north of Syria, Lebanon, and Israel $(|\mathrm{Z}|>1.96)$.

For April, statistically significant downward trends ( 0.2 to $0.6 \mathrm{~mm} /$ year) were detected in the northeast, east, west, and northwest of Iran, central and south of Turkey, north of Iraq, north of Syria, and north of Israel. A significant $(|\mathrm{Z}|>1.96)$ upward trend was detected in the north of Turkey $(0.3$ to $0.5 \mathrm{~mm} / \mathrm{year})$ (Figures 3 and 4). For May and Jun, significant $(|\mathrm{Z}|>1.96)$ downward trends $(0.2$ to $0.4 \mathrm{~mm} /$ year $)$ were observed in the northeast and east of Iran, southwest of Saudi Arabia, central parts of Turkey and west of Yemen and upward trends in some eastern and northern parts of Turkey ( 0.2 to $0.4 \mathrm{~mm}$ ). For July and August, downward trends were detected in the west of Iran and southwest of Saudi and west of Yemen, south of Egypt, and northeast of Sudan $(|Z|>1.96)$. For September, October, and November, statistically significant upward trends were detected in most parts of Turkey and northwest of Iran (Figures 3 and 4). Also for December, upward trends were detected in the north of Turkey and west of Iran, and statistically significant downward trends were detected in the southeast of Iran, north of Iraq and Syria, Israel, southwest of Turkey, Lebanon and Israel, Jordan and Cyprus (figure 3 and 4).

\subsection{Monthly trends for potential evapotranspiration (PET)}

Trend analysis of monthly PET was conducted for each month for the 71 years study period (Figures 5 and 6). The higher the PET values indicates the potential of the area for releasing water to the atmosphere and getting drier. 
Peer-reviewed version available at Theoretical and Applied Climatology 2020; doi:10.1007/s00704-020-03370-6

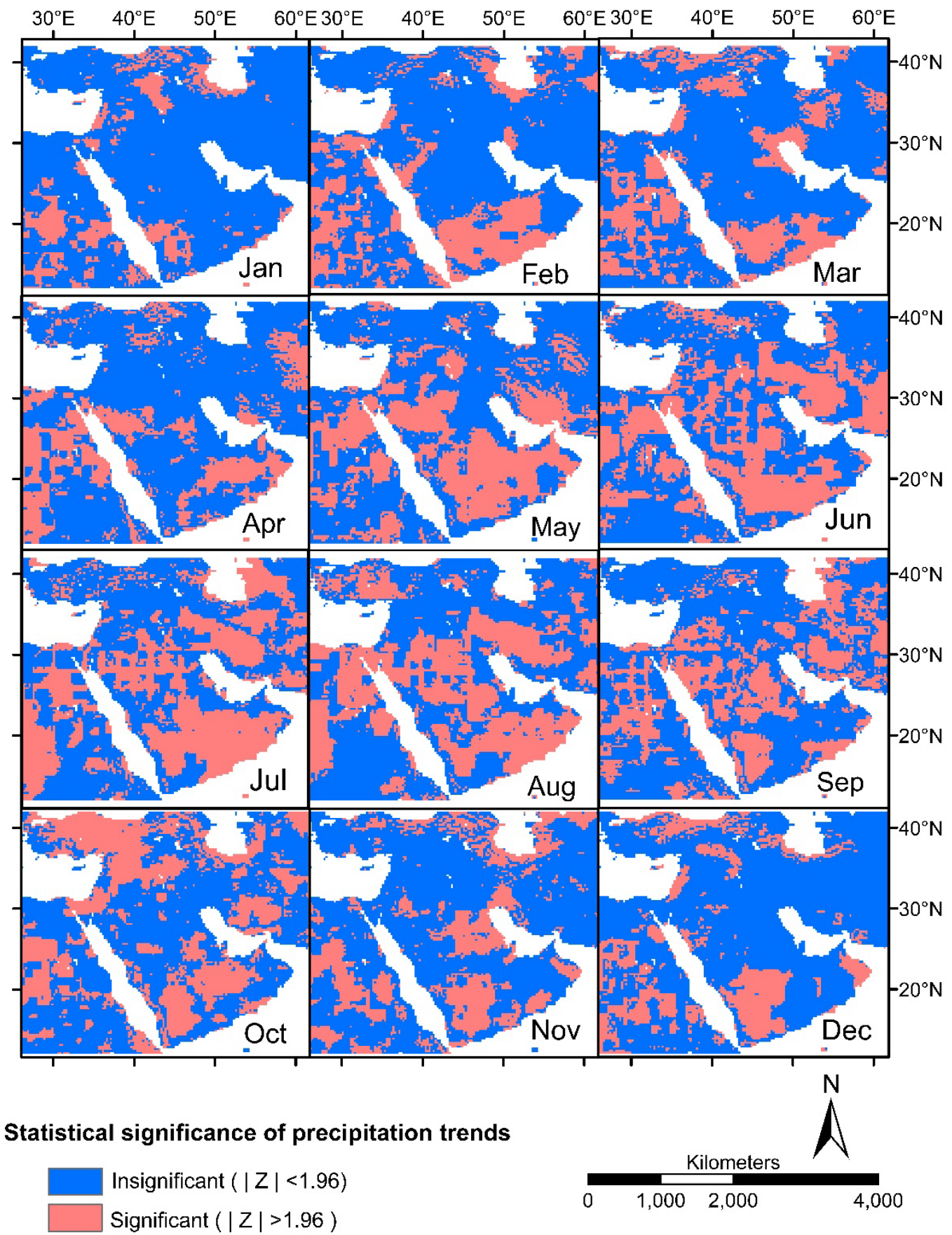

Figure 3. Statistical significance of the calculated trends for monthly precipitation. The area was divided into two parts, the statistically significant area where the absolute values of the $\mathrm{Z}$ statistic for calculated trends were less than $1.96(|Z|<1.96)$, and the statistically significant area where the absolute values of the $\mathrm{Z}$ statistic were more than $1.96(|\mathrm{Z}|>1.96)$ 


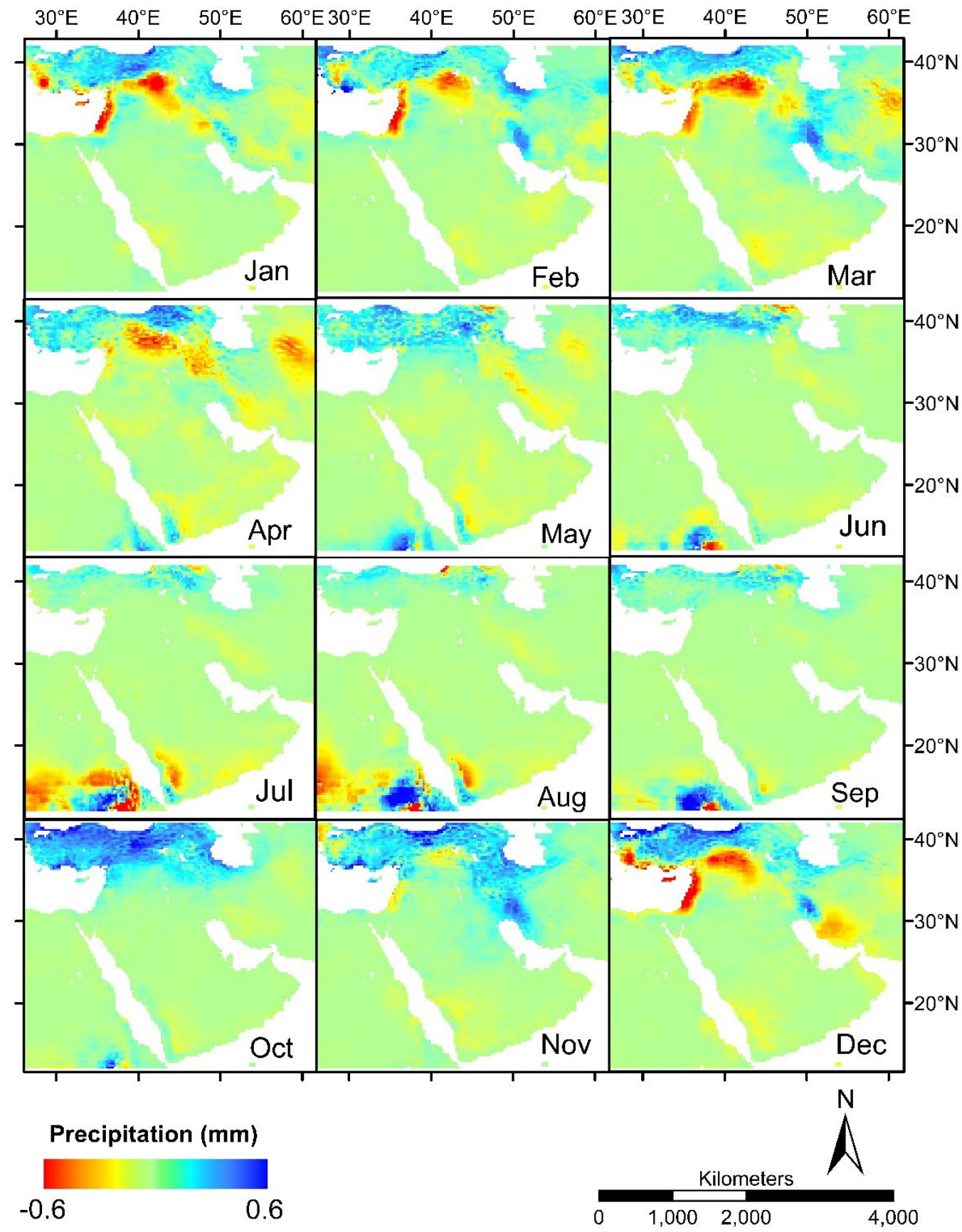

Figure 4. The slope (mm per month) of the trends $(\beta)$ for monthly precipitation from 1948 to 2018. 


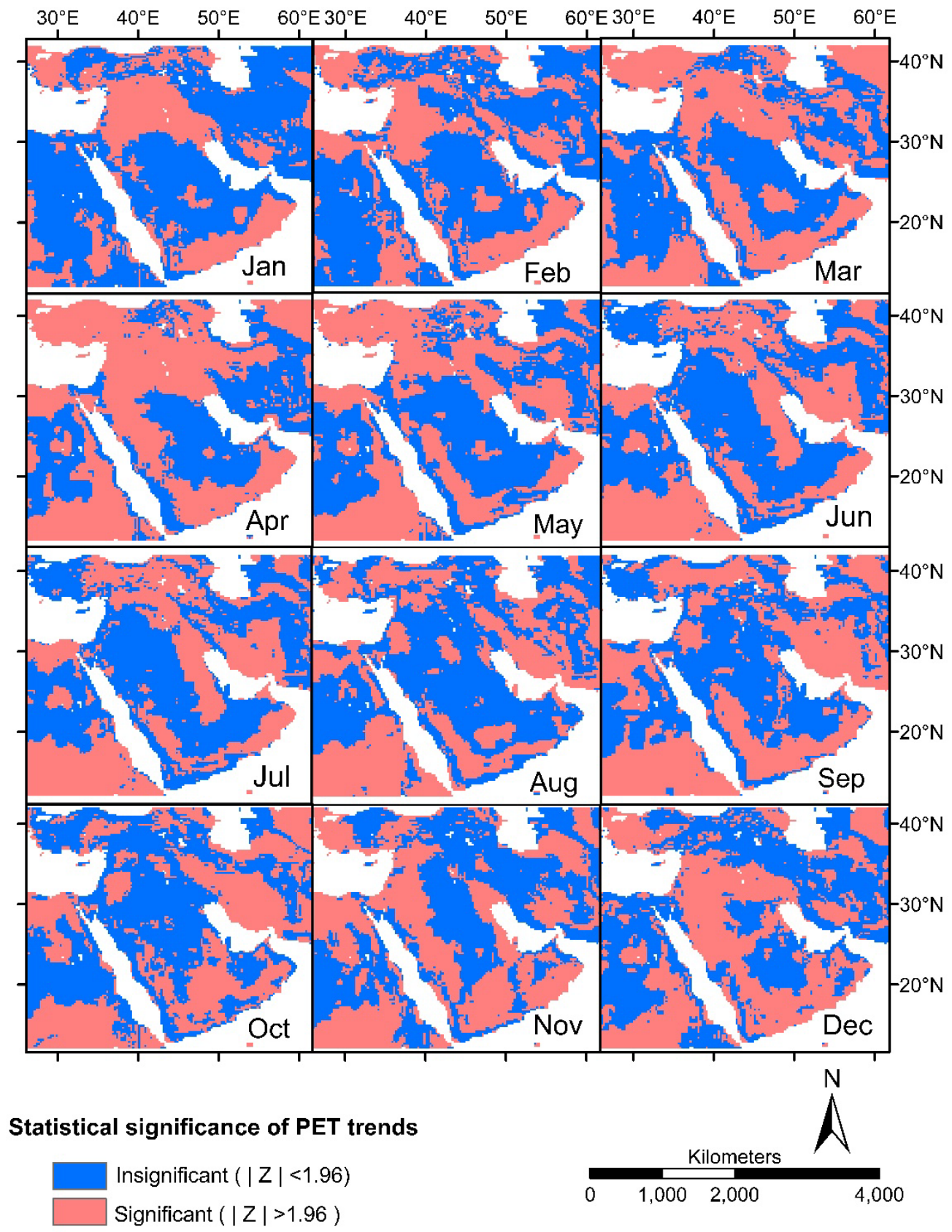

Figure 5. Statistical significance of the calculated trends for monthly potential evapotranspiration (PET).

For January through September, significant $(|Z|>1.96)$ downward trends were observed in the north and south of Iran ( 0.1 to $0.6 \mathrm{~mm} /$ year), central through eastern parts of Saudi Arabia (0.1 to $0.4 \mathrm{~mm} /$ year), and along the Nile river ( 0.05 to $0.28 \mathrm{~mm} /$ year) and west of Turkey (up to $0.7 \mathrm{~mm} /$ year). Upward trends were 
observed in the West of Iran, Iraq, Syria, Turkey, Jordan, Lebanon, Egypt, Sudan, Eritrea, and Yemen (ranging from 0.1 to $1.4 \mathrm{~mm} /$ year).

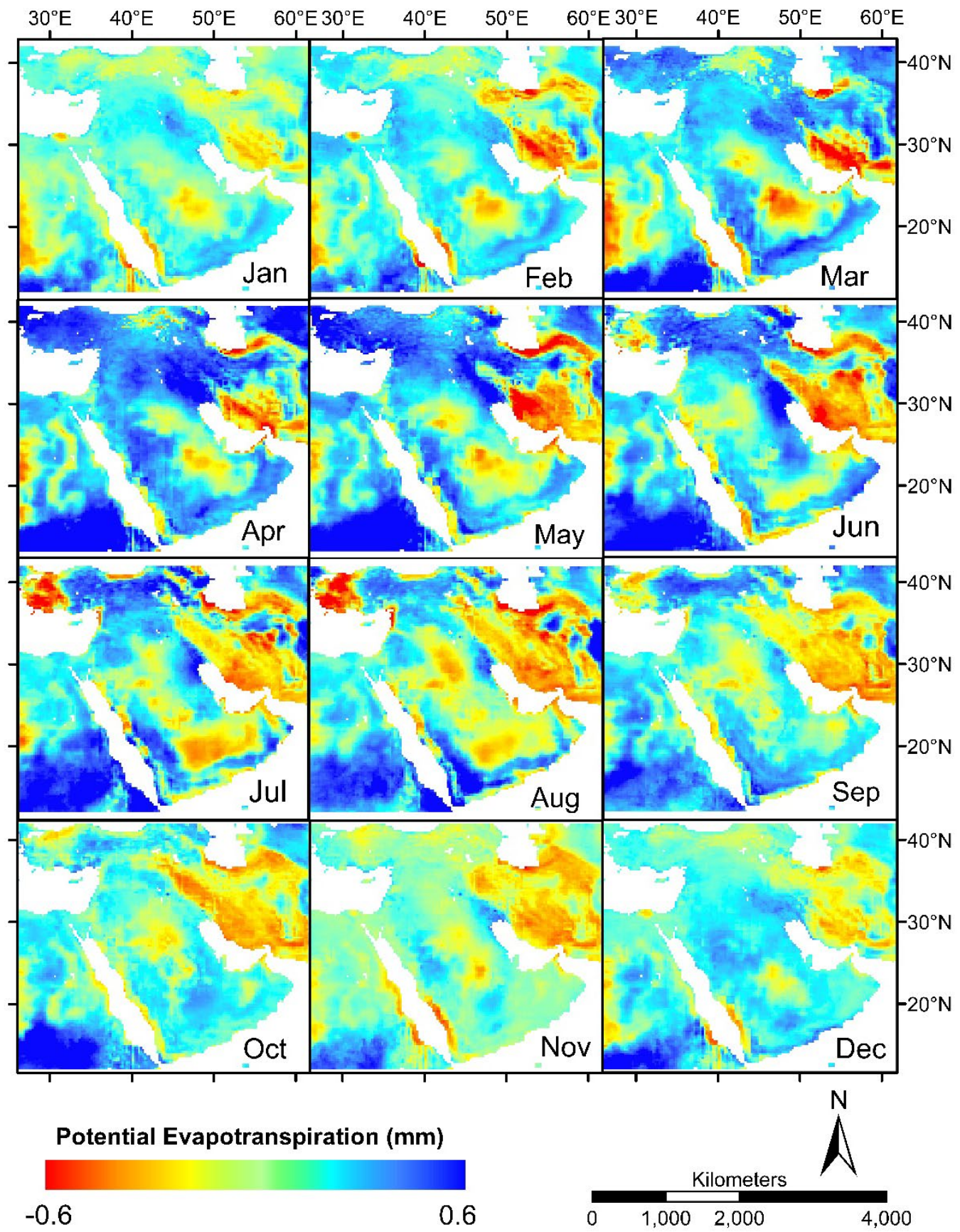

Figure 6. The slope (mm per month) of the trends $(\beta)$ for monthly potential evapotranspiration (PET) from 1948 to 2018. 
For October and November, statistically significant downward trends (up to $0.5 \mathrm{~mm} /$ year) were observed in central and south of Saudi Arabia, UAE, southeast of Iran, and along the Nile river (Figures 5 and 6) and significant upward (up to $0.5 \mathrm{~mm} /$ year) trends were detected in south of Egypt and north of Sudan. For December, statistically significant upward trends were detected in most parts of Saudi Arabia through Syria and the south of Turkey. The statistically significant trends in the north, northeast, and south of Iran were downward (up to $0.5 \mathrm{~mm} /$ year).

\subsection{Monthly trends for aridity index (AI)}

The monthly aridity index (AI) was calculated (P/PET) for each month (Figures 7 and 8). As we mentioned earlier, drier areas have a lower aridity index. The negative (downward) AI trends indicate that the area is getting drier. The upward AI trends suggest that the area is getting wetter.

For January, February, March, and April statistically significant $(|Z|>1.96)$ downward trends were observed in the west and south of Turkey ( 0.008 to $0.08 \mathrm{~mm} /$ year $)$, east of Iran ( 0.002 to $0.013 \mathrm{~mm} / \mathrm{month})$, north of Iraq (0.002 to $0.003 \mathrm{~mm} /$ year), entire Syria (0.0022 to 0.024), Cyprus (up to $0.006 \mathrm{~mm} /$ year), Israel (0.002 to 0.013 ), west of Jordan (up to $0.004 \mathrm{~mm} /$ year), southwest of Saudi Arabia (up to 0.001) and north of Egypt (figures 7 and 8). The magnitude of the downward trends in January, February, March, and April that account for 22 to 106 percent decrease in aridity index indicates a dramatic increase in dryness in those areas. Upward trends were also observed in the north of Iran (0.001 to $0.008 \mathrm{~mm} / \mathrm{year})$, the northwestern and eastern part of Turkey (0.004 to $0.015 \mathrm{~mm} /$ year). For May, a statistically significant downward trend was observed in southwest Iran, southwest of Saudi Arabia, Oman, and Yemen (Figures 7 and 8). In June, July, August, and September, Upward trends were detected in some parts of north and northeast Turkey (up to $0.0017 \mathrm{~mm} /$ year) and a downward trend in the south of Egypt and southwest of Saudi Arabia (0.001 to $0.003 \mathrm{~mm} /$ year). For October, a significant upward trend ( up to $0.005 \mathrm{~mm} /$ year) was detected in most parts of Turkey and north of Iran. In November, upward trends were detected in the north and southwest of Iran (up to $0.003 \mathrm{~mm} / \mathrm{year}$ ), and east of Saudi Arabia. Significant downward trends were identified in the 
southwest of Saudi Arabia and west of Yemen (up to0.0007 mm/year). Upward trends in December were detected in the north of Iran (up to $0.015 \mathrm{~mm} /$ year). Significant $(|\mathrm{Z}|>1.96)$ downward trends were detected in the north of Iraq, Syria, Jordan, Lebanon, Israel (up to, southwest Saudi Arabia, and Oman (up to 0. 001) (Figures 7 and 8).

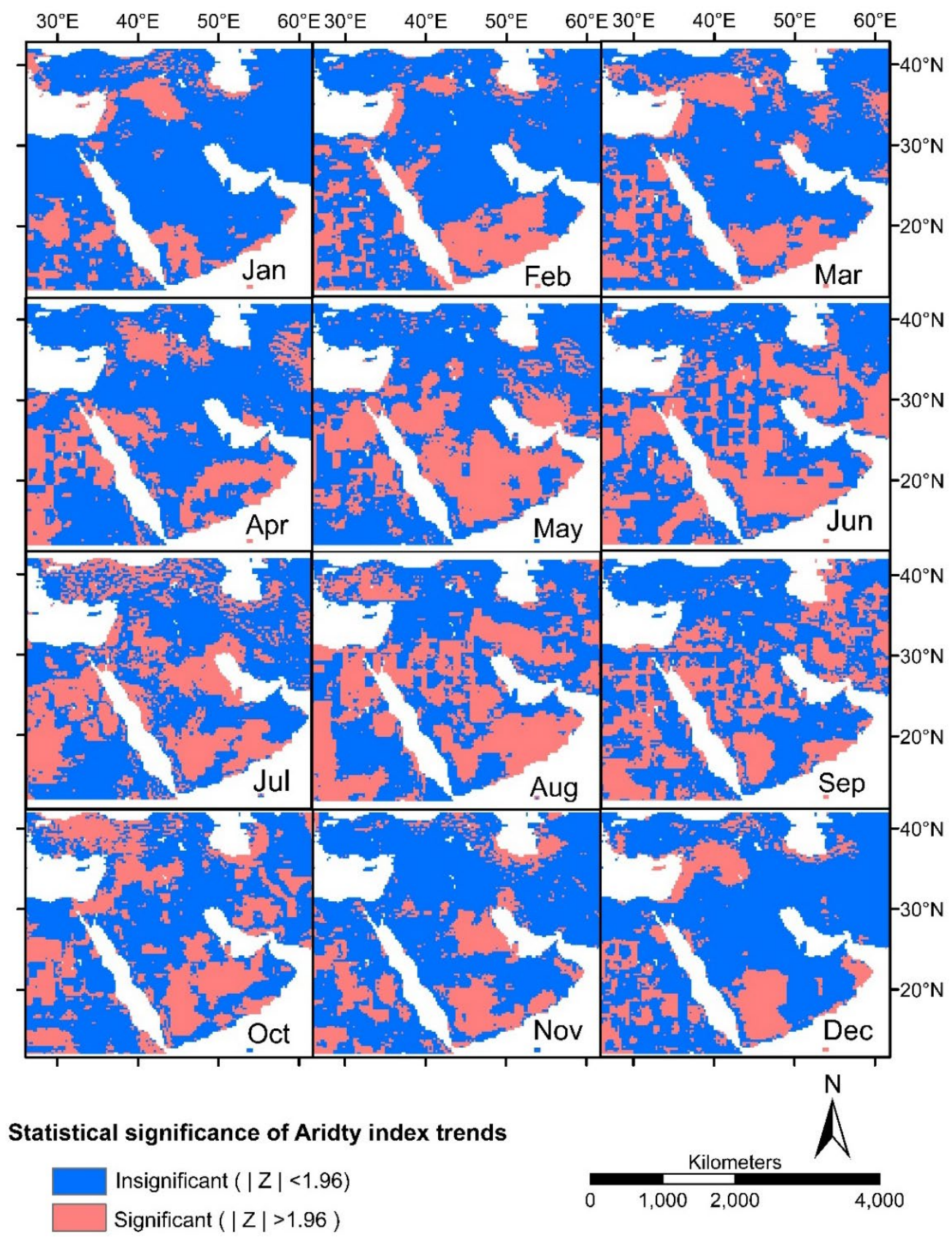

Figure 7. Statistical significance of the calculated trends for monthly aridity index (AI). 


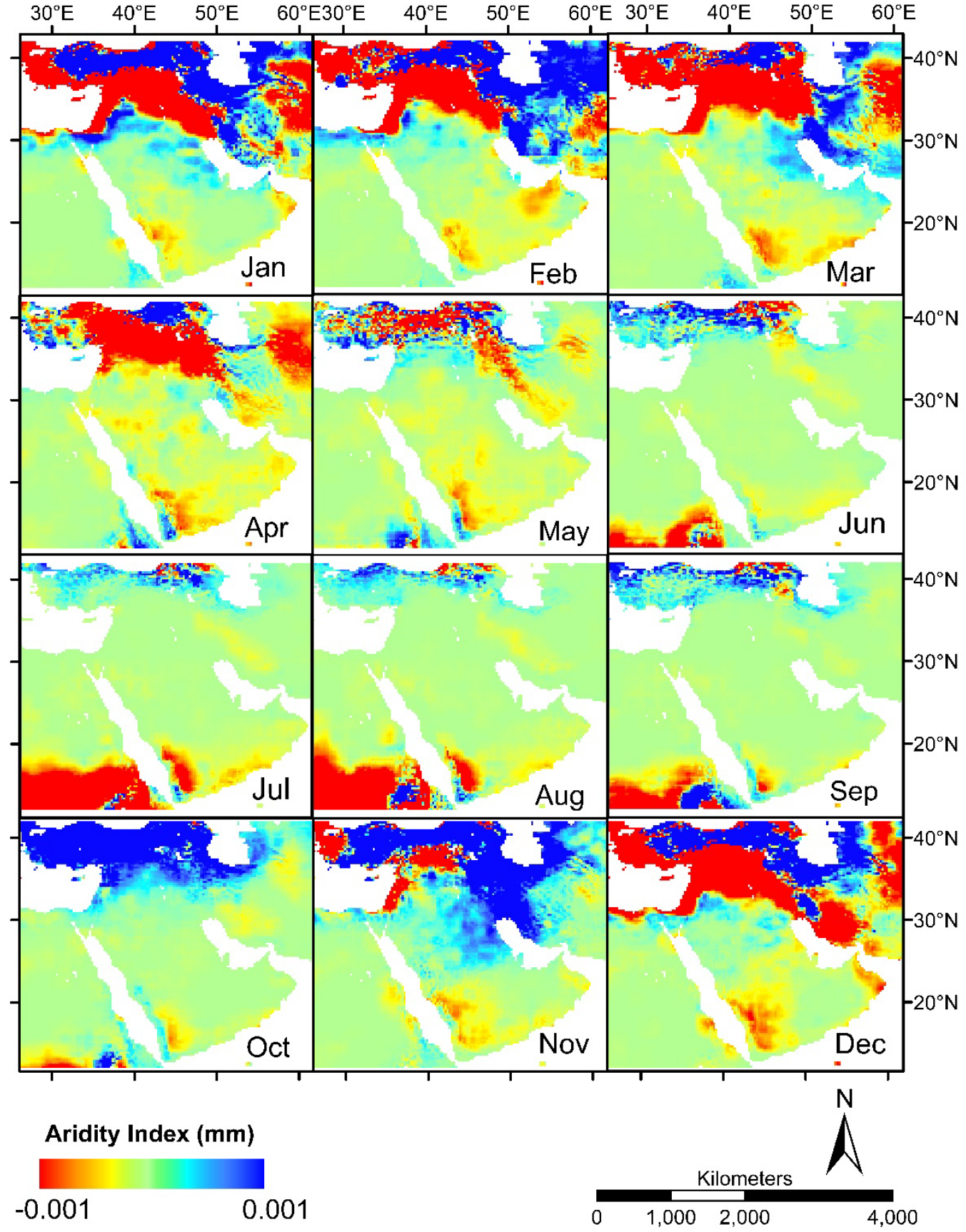

Figure 8. The slope (mm per month) of the trends $(\beta)$ for monthly aridity index (AI) from 1948 to 2018. 


\subsection{Annual trends for precipitation, potential evapotranspiration, and aridity index}

The annual trend for precipitation and statistical significance (figure 9) of the annual trends were calculated for the entire study area. The relative changes were also calculated to show the changes in percentage. Statistically significant $(|Z|<1.96)$ downward trends were detected in eastern (2 to 38 percent; figure 10$)$, southern ( 1 to 15 percent; figure 10), and northwest (6 to 23 percent; figure 10) of Iran, west (4 to 12 percent; figure 10) and south of Turkey ( 5 to 25 percent; figure 10), South of Saudi Arabia and Yemen (11 to 40 percent; figure 10), central through south of Egypt and north of Sudan (16 to 98 percent ), north of Iraq (5 to 17 percent, figure 10) and Syria (7 to 16 percent; figure 10), and Israel (19 to 48 percent; figure 10). The highest downward and upward trends were detected in the north of Sudan (96 percent; figure 10) and east of Saudi Arabia (61 percent, figure 10).

The detected downward trends are consistent with the results from previous studies by Patal and Kahya, 2005 in Turkey; Kafle and Bruins, 2007, in Israel; and Tabari and Talaee, 2011, in Iran. Significant upward trends were detected in the southwest of Iran, west of Iraq, Jordan, south of Syria, Kuwait, Qatar, and the east and north of Saudi Arabia (10 to 61 percent; figure 10). Statistically significant positive trends (ranging from 5 to 25 percent; figure 10) were also observed in some parts of the central turkey, central to the north of Iran.

The annual trend for PET and statistical significance (figure 9) of the annual trends were calculated for the entire study area. Statistically significant downward trends (ranging from 3 to 7 percent; figure 10) were observed in the north of Iran, central Saudi Arabia, and west of Egypt. Statistically significant positive trends were detected in most parts of Egypt, northwest of Iran, Iraq, Syria, north of Saudi Arabia, and east and south of Sudan (up to 6 percent; figure 10). Table 2 shows the percentage of the area with positive and negative trends relative to all detected significant trends and also the maximum and the minimum detected relative change for each variable. 

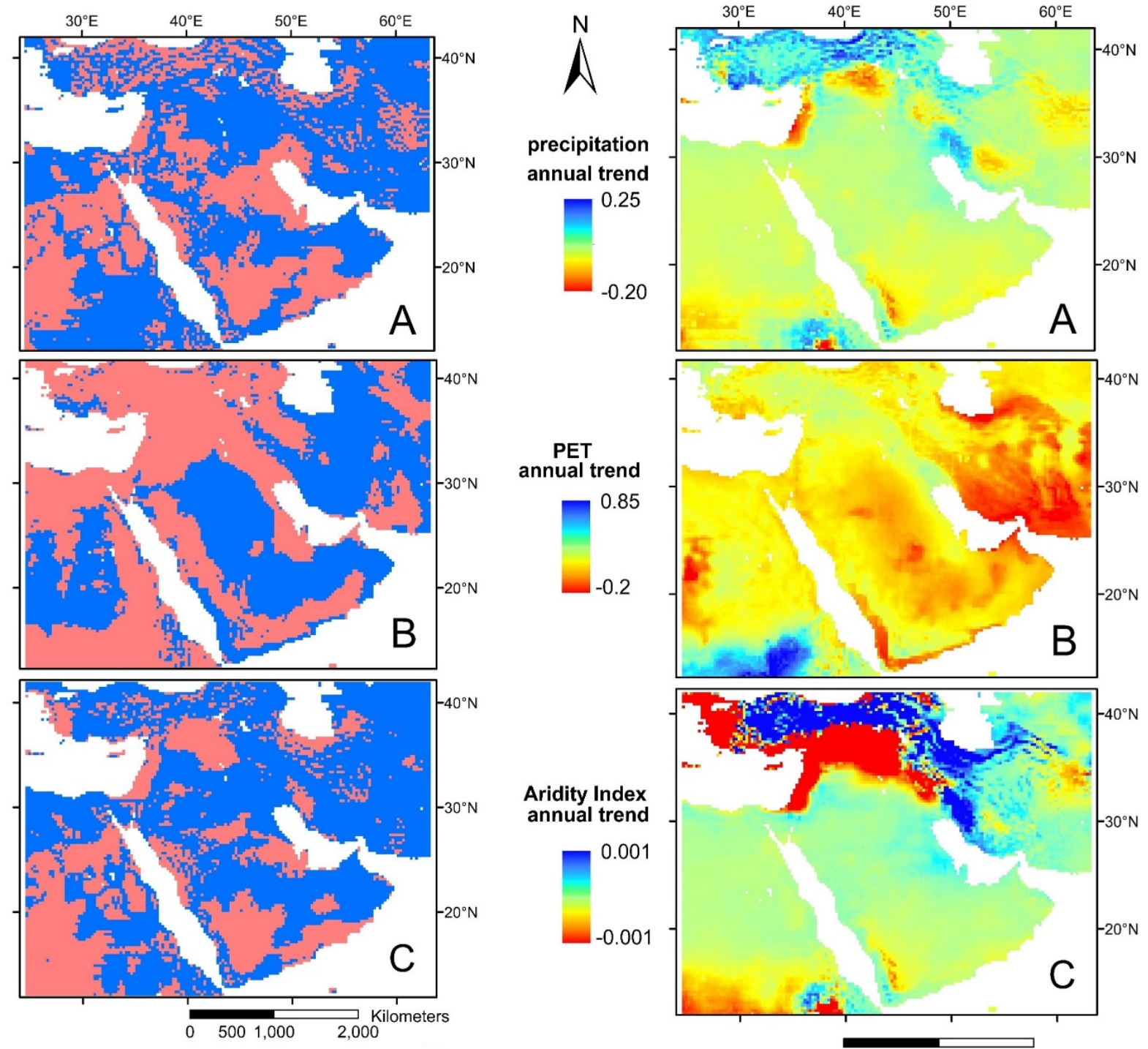

Statistical significance of precipitation trends

Insignificant $(|Z|<1.96)$

Significant $(|Z|>1.96)$

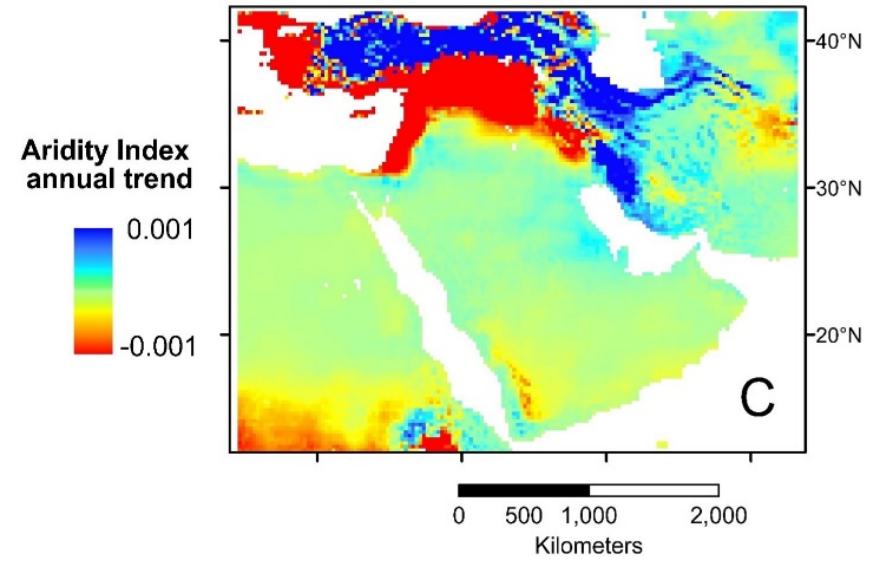

Figure 9. The statistical significance and slope (mm per month) of the annual trends $(\beta)$ from 1948 to 2018 for (A) precipitation; (B) potential evapotranspiration (PET); and (C) aridity index (AI) 
Table 2. Percentage of areas with upward and downward trends relative to all significant trends. The maximum and minimum detected relative change for each variable (P, PET, and AI)

\begin{tabular}{ccccc}
\hline & \multicolumn{2}{c}{ Area (\%) } & \multicolumn{2}{c}{ Relative change (\%) } \\
\hline Variable & Upward & Downward & Max & Min \\
\hline P & 56.4 & 43.6 & 63.39 & -101.18 \\
\hline PET & 93.98 & 6.02 & 19.92 & -6.07 \\
\hline AI & 37.53 & 62.47 & 72.83 & -96.60
\end{tabular}

P: Precipitation; PET: Potential evapotranspiration; AI: Aridity index

Annual trends for aridity index (AI) and their statistical significance were reported in figure 9, respectively. Statistically significant increase in aridity (downward trend in aridity index) were detected in eastern and western parts of Iran (up to 35 percent), west and central parts of Turkey and north of Iraq (up to 33 percent; figure 10), Syria (up to 37 percent; figure 10), west of Jordan and Israel (up to 58 percent; figure 10), central and south of Saudi Arabia (26 to 71 percent; figure 10), north of Sudan (up to 96 percent; figure 10), north and south of Egypt ( 32 to 89 percent; figure 10). Statistically significant decrease in aridity (increase in aridity index) were detected in some parts of central Iran to the north (up to 27 percent), central part of Turkey (up to 25 percent; figure 10), central to north of Saudi Arabia (up to 20 percent; figure 10), Qatar (up to 23; figure 10); UAE (up to 25 percent; figure 10), and north of Egypt (up to 21 percent figure 10). The highest increase in aridity has occurred in the north of Sudan, with a 96 percent decrease in aridity index. The highest decrease in aridity (increase in aridity index) has occurred in the east of Saudi Arabia and west of Qatar (61 percent). 


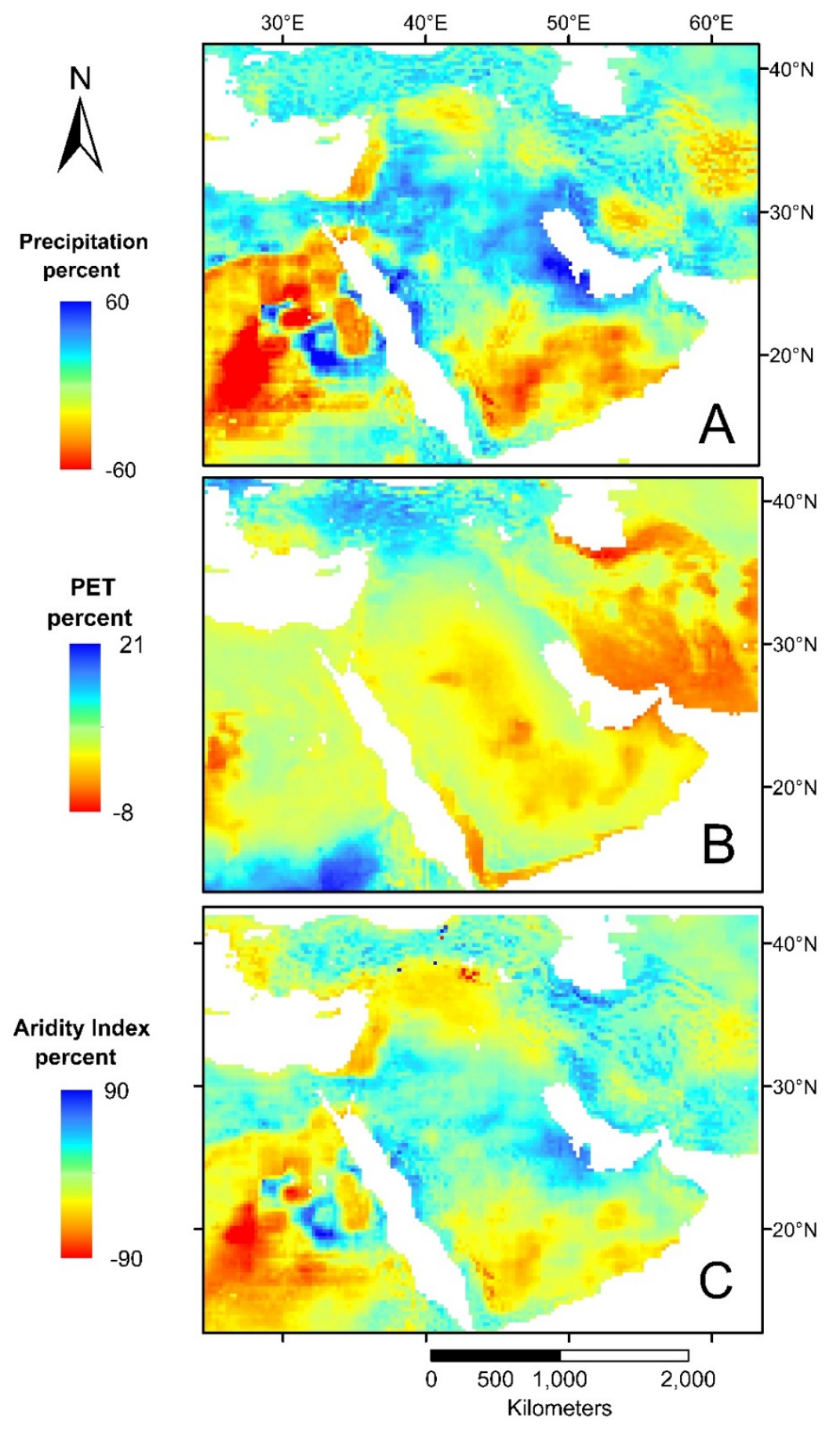

Figure 10. The relative change (in percent) for each variable from 1948 to 2018 for (A) precipitation; (B) potential evapotranspiration (PET); and (C) aridity index (AI) 


\section{Conclusion}

A pixel-wise trend analysis was conducted on model-derived precipitation, potential evapotranspiration, and aridity index at a monthly and annual timescale over the Middle East and adjacent region for a 71-year study period. The analysis of the time series data revealed the majority of the Middle Eastern countries are moving toward more aridity (ranging from 20 to 96 percent decrease in aridity index). At a monthly time scale, the most pronounced increase and decrease in aridity were observed in April and October, respectively. Decreasing trends in aridity were observed in the north and central parts of Turkey and the west of Iran from October to March. Increased aridity was detected Over west and south of Turkey, Syria, East of Iran, Iraq, Israel, Jordan, Lebanon, south of and southwest of Saudi Arabia, south of Egypt in November to Jun. At an annual time scale, aridity increased (20 to 96 percent) in the majority of the countries in the study area. A significant decrease in precipitation was observed in the area with positive aridity trends (negative aridity index) in Jan, Feb, Mar, April, May, and December. Positive precipitation trends were detected in October and November in most parts of the region. At an annual timescale, aridity has increased in most countries of the region. The increased aridity ranged from 20 to 96 percent and was detected in Turkey, Iran, Iraq, Israel, Jordan, Lebanon, Syria, Saudi Arabia, Sudan, and Egypt. The decrease in aridity index was observed in the east of Saudi Arabia, Qatar, north of Iran, and some parts of central Turkey. The areas of increased aridity were correlated with the areas with negative precipitation trends.

The sources of errors in our study are related to (1) Uncertainty in the variables (precipitation, potential evapotranspiration, and calculated aridity index) that were used for the spatiotemporal trend analysis; and (2) errors introduced by the applied statistical methods. In this research, we did not consider the errors related to the dataset. Those errors could be related to measurements, and/or the interpolation techniques were used to generate the precipitation and potential evapotranspiration data.

According to the World Bank (2007), the majority of countries in ME cannot meet their current water demands. This study shows that many of those countries are moving toward severe aridity due to a 
combined effect of the decline in precipitation and the increase in potential evapotranspiration. Because the ME region is one of the most water-scarce regions in the world, proper short term and long term water management is essential to meet the water demands for the growing population of the region.

\section{References:}

Almazroui, Mansour, et al. "Trends of temperature extremes in Saudi Arabia." International Journal of Climatology 34.3 (2014): 808-826. https://doi.org/10.1002/joc.3722

Bouraoui, F., et al. "Evaluation of the impact of climate changes on water storage and groundwater recharge at the watershed scale." Climate Dynamics 15.2 (1999): 153-161.

https://doi.org/10.1007/s003820050274

Bryan, K. The steric component of sea level rise associated with enhanced greenhouse warming: a model study. Climate Dynamics 12, 545-555 (1996). https://doi.org/10.1007/BF00207938

Chen, W., Dong, B. Anthropogenic impacts on recent decadal change in temperature extremes over China: relative roles of greenhouse gases and anthropogenic aerosols. Clim Dyn 52, 3643-3660 (2019). https://doi.org/10.1007/s00382-018-4342-9

Douville, .H., Chauvin, .F., Planton, .S. et al. Sensitivity of the hydrological cycle to increasing amounts of greenhouse gases and aerosols. Climate Dynamics 20, 45-68 (2002). https://doi.org/10.1007/s00382-002$\underline{0259-3}$

Dinpashoh, Yagob, et al. "Trends in reference crop evapotranspiration over Iran." Journal of Hydrology 399.3-4 (2011): 422-433. https://doi.org/10.1016/j.jhydrol.2011.01.021 
D'Oria, Marco, Massimo Ferraresi, and Maria Giovanna Tanda. "Historical trends and high-resolution future climate projections in northern Tuscany (Italy)." Journal of hydrology 555 (2017): 708-723. https://doi.org/10.1016/j.jhydrol.2017.10.054

Falkenmark, Malin, and Mats Lannerstad. "Consumptive water use to feed humanity-curing a blind spot." (2005). https://doi.org/10.5194/hess-9-15-2005

Fathian, Farshad, Saeed Morid, and Ercan Kahya. "Identification of trends in hydrological and climatic variables in Urmia Lake basin, Iran." Theoretical and Applied Climatology 119.3-4 (2015): 443-464. https://doi.org/10.1007/s00704-014-1120-4

Gado, T.A., El-Hagrsy, R.M. \& Rashwan, I.M.H. Spatial and temporal rainfall changes in Egypt. Environ Sci Pollut Res 26, 28228-28242 (2019). https://doi.org/10.1007/s11356-019-06039-4

Gholami, V., Torkaman, J. \& Dalir, P. Simulation of precipitation time series using tree-rings, earlywood vessel features, and artificial neural network. Theor Appl Climatol 137, 1939-1948 (2019). https://doi.org/10.1007/s00704-018-2702-3

Gholami, V., Ahmadi Jolandan, M. \& Torkaman, J. Evaluation of climate change in northern Iran during the last four centuries by using dendroclimatology. Nat Hazards 85, 1835-1850 (2017). https://doi.org/10.1007/s11069-016-2667-4

Gilbert, Richard O. Statistical methods for environmental pollution monitoring. John Wiley \& Sons, 1987.

Glickman, Todd S., and Walter Zenk. Glossary of meteorology. American Meteorological Society, 2000. 
Grove, A. T. "The arid environment." Plants for Arid Lands. Springer, Dordrecht, 1985. 9-18.

Güçlü, Yavuz Selim. "Improved visualization for trend analysis by comparing with classical MannKendall test and ITA." Journal of Hydrology (2020): 124674.

https://doi.org/10.1016/j.jhydrol.2020.124674

Hasan, E., Tarhule, A., Zume, J.T. et al. +50 Years of Terrestrial Hydroclimatic Variability in Africa's Transboundary Waters. Sci Rep 9, 12327 (2019). https://doi.org/10.1038/s41598-019-48813-x

Hollander, Myles, Douglas A. Wolfe, and Eric Chicken. Nonparametric statistical methods. Vol. 751. John Wiley \& Sons, 2013.

Irmak, S., Kabenge, I., Skaggs, K. E., \& Mutiibwa, D."Trend and magnitude of changes in climate variables and reference evapotranspiration over 116-yr period in the Platte River Basin, central NebraskaUSA." Journal of Hydrology 420 (2012): 228-244. https://doi.org/10.1016/j.jhydrol.2011.12.006

Jhajharia D, Dinpashoh Y, Kahya E, Singh VP, Fakheri-Fard A. Trends in reference evapotranspiration in the humid region of northeast India. Hydrological Processes 26.3 (2012): 421-435. https://doi.org/10.1002/hyp. 8140

Jhajharia D, Dinpashoh Y, Kahya E, Choudhary RR and. Singh VP "Trends in temperature over Godavari river basin in southern peninsular India." International Journal of Climatology 34.5 (2014): 1369-1384. https://doi.org/10.1002/joc.3761 
Joffe, George. "The Impending Water Crisis in the MENA Region." The International Spectator 51.3 (2016): 55-66. https://doi.org/10.1080/03932729.2016.1198069

Kafle, H.K., Bruins, H.J. Climatic trends in Israel 1970-2002: warmer and increasing aridity inland. Climatic Change 96, 63-77 (2009). https://doi.org/10.1007/s10584-009-9578-2

Kamga, François Mkankam. "Impact of greenhouse gas induced climate change on the runoff of the Upper Benue River (Cameroon)." Journal of hydrology 252.1-4 (2001): 145-156.

https://doi.org/10.1016/S0022-1694(01)00445-0

Kendall, Maurice G. "A new measure of rank correlation." Biometrika 30.1/2 (1938): 81-93.

Livneh, B., Deems, J. S., Schneider, D., Barsugli, J. J., \& Molotch, N. P. "Filling in the gaps: Inferring spatially distributed precipitation from gauge observations over complex terrain." Water Resources Research 50.11 (2014): 8589-8610. https://doi.org/10.1002/2014WR015442

Llopart, M., Simões Reboita, M. \& Porfírio da Rocha, R. Assessment of multi-model climate projections of water resources over South America CORDEX domain. Clim Dyn 54, 99-116 (2020). https://doi.org/10.1007/s00382-019-04990-z

Mann, Henry B. "Nonparametric tests against trend." Econometrica: Journal of the Econometric Society (1945): 245-259.

Mohammadian, Mohsen, Ramin Arfania, and Hossein Sahour. "Evaluation of SEBS algorithm for estimation of daily evapotranspiration using landsat-8 dataset in a Semi-Arid Region of Central Iran." Open Journal of Geology 7.3 (2017): 335-347. https://doi.org/10.4236/ojg.2017.73023 
Mudelsee, Manfred. "Trend analysis of climate time series: A review of methods." Earth-science reviews 190 (2019): 310-322. https://doi.org/10.1016/j.earscirev.2018.12.005

Oki, Taikan, and Shinjiro Kanae. "Global hydrological cycles and world water resources." science 313.5790 (2006): 1068-1072. DOI: 10.1126/science.1128845

Partal, Turgay, and Ercan Kahya. "Trend analysis in Turkish precipitation data." Hydrological Processes: An International Journal 20.9 (2006): 2011-2026. https://doi.org/10.1002/hyp.5993

Pradhan, R.K., Sharma, D., Panda, SK et al. Changes of precipitation regime and its indices over Rajasthan state of India: impact of climate change scenarios experiments. Clim Dyn 52, 3405-3420 (2019). https://doi.org/10.1007/s00382-018-4334-9

Risbey, J.S. Dangerous climate change and water resources in Australia. Reg Environ Change 11, 197-203 (2011). https://doi.org/10.1007/s10113-010-0176-7

Roudi-Fahimi, Farzaneh, and Mary Mederios Kent. Challenges and opportunities--the population of the Middle East and North Africa. Population Reference Bureau, 2007.

Sahour, H.; Sultan, M.; Vazifedan, M.; Abdelmohsen, K.; Karki, S.; Yellich, J.A.; Gebremichael, E.; Alshehri, F.; Elbayoumi, T.M. Statistical Applications to Downscale GRACE-Derived Terrestrial Water Storage Data and to Fill Temporal Gaps. Remote Sens. 2020, 12, 533. https://doi.org/10.3390/rs12030533

Said, M., Komakech, H.C., Munishi, L.K. et al. Evidence of climate change impacts on water, food and energy resources around Kilimanjaro, Tanzania. Reg Environ Change 19, 2521-2534 (2019). https://doi.org/10.1007/s10113-019-01568-7 
Schilling, J., Hertig, E., Tramblay, Y. et al. Climate change vulnerability, water resources and social implications in North Africa. Reg Environ Change 20, 15 (2020). https://doi.org/10.1007/s10113-02001597-7

Sen, Pranab Kumar. "Estimates of the regression coefficient based on Kendall's tau." Journal of the American statistical association 63.324 (1968): 1379-1389.

Shifteh Some'e, B., Ezani, A. \& Tabari, H. Spatiotemporal trends of aridity index in arid and semi-arid regions of Iran. Theor Appl Climatol 111, 149-160 (2013). https://doi.org/10.1007/s00704-012-0650-x

Soto-Navarro, J., Jordá, G., Amores, A. et al. Evolution of Mediterranean Sea water properties under climate change scenarios in the Med-CORDEX ensemble. Clim Dyn 54, 2135-2165 (2020). https://doi.org/10.1007/s00382-019-05105-4

Tabari, Hossein, and Mohammad-Bagher Aghajanloo. "Temporal pattern of aridity index in Iran with considering precipitation and evapotranspiration trends." International Journal of Climatology 33.2 (2013): 396-409. https://doi.org/10.1002/joc.3432

Tehrani, E. Nikzad, H. Sahour, and M. J. Booij. "Trend analysis of hydro-climatic variables in the north of Iran." Theoretical and applied climatology 136.1-2 (2019): 85-97. https://doi.org/10.1007/s00704-0182470-0

Terink, Wilco, Walter Willem Immerzeel, and Peter Droogers. "Climate change projections of precipitation and reference evapotranspiration for the Middle East and Northern Africa until 2050." International journal of climatology 33.14 (2013): 3055-3072. https://doi.org/10.1002/joc.3650 
Theil, Henri. "A rank-invariant method of linear and polynomial regression analysis." Henri Theil's contributions to economics and econometrics. Springer, Dordrecht, 1992. 345-381

Von Storch, Hans. "Misuses of statistical analysis in climate research." Analysis of climate variability. Springer, Berlin, Heidelberg, 1999. 11-26.

Wang, Yongdong, et al. "Paleo-CO2 variation trends and the Cretaceous greenhouse climate." EarthScience Reviews 129 (2014): 136-147. https://doi.org/10.1016/j.earscirev.2013.11.001

World Bank. Making the most of scarcity. Accountability for better water management results in the Middle East and North Africa. MENA Development Report, 2007. https://doi.org/10.1596/978-0-82136925-8

Xing, W., Wang, W., Shao, Q., Yong, B., Liu, C., Feng, X., \& Dong, Q. (2018). Estimating monthly evapotranspiration by assimilating remotely sensed water storage data into the extended Budyko framework across different climatic regions. Journal of hydrology, 567, 684-695. https://doi.org/10.1016/j.jhydrol.2018.10.014

Ziervogel, G., Satyal, P., Basu, R. et al. Vertical integration for climate change adaptation in the water sector: lessons from decentralisation in Africa and India. Reg Environ Change 19, 2729-2743 (2019). https://doi.org/10.1007/s10113-019-01571-y 